\title{
Scapular dyskinesis was not associated with pain and function in male adolescent athletes
}

\author{
Discinese escapular não está associada à dor e função no ombro dos adolescentes atletas
}

Valéria Mayaly Alves de Oliveira1 ${ }^{1}$, Hitalo Andrade da Silva², Ana Carolina Rodarti Pitangui ${ }^{1}$, Muana Hiandra Pereira dos Passos ${ }^{1}$, Rodrigo Cappato de Araújo²

DOI 10.5935/2595-0118.20180009

\section{ABSTRACT}

BACKGROUND AND OBJECTIVES: Scapular dyskinesis has been associated to shoulder injuries and pain. However, this relationship with adolescent athletes is not well established. The objective of this study was to evaluate scapular dyskinesis in young athletes and its association with pain or shoulder function.

METHODS: 178 male adolescent athletes (14.58 \pm 2.16 years) were evaluated. The subjects completed the Quick Disability Arm Shoulder Hand questionnaire. Body mass, height, shoulder internal rotation and Closed Kinetic Chain Upper Extremity Stability test were measured. A dynamic visual method was applied to assess dyskinesis. Binary logistic regression was applied to analyze the association between dyskinesis and other variables. The comparison between groups with and without dyskinesis was made by the Mann-Whitney and $t$-test, accepting a statistical significance of $\mathrm{p}<0.05$.

RESULTS: The dyskinesis prevalence was $56.7 \%$ and this condition was not associated with shoulder pain. Younger athletes are $159 \%$ more likely to have dyskinesis, while those who practice more than one hour a day for three times a week are $77 \%$ more likely to have the same outcome. No difference in shoulder function was found.

CONCLUSION: Scapular dyskinesis is not associated with pain and does not affect shoulder function in adolescent athletes. Sports modality, age and training volume seem to induce changes in scapula movement.

Keywords: Adolescents, Athletes, Athletic performance, Pain, Shoulder.

\footnotetext{
1. Universidade Federal da Paraíba, Departamento de Fisioterapia, João Pessoa, PB, Brasil. 2. Universidade de Pernambuco, Programa de Hebiatria, Recife, PE, Brasil.

Submitted in September 03, 2017.

Accepted for publication in January 22, 2018

Conflict of interests: none - Sponsoring sources: none

Correspondence to:

Avenida Umbuzeiro, 581 - Manaíra

58038-180 João Pessoa, PB, Brasil.

E-mail: muana.pereira@hotmail.com

(C) Sociedade Brasileira para o Estudo da Dor
}

\section{RESUMO}

JUSTIFICATIVA E OBJETIVOS: A discinese escapular tem sido associada a lesóes e dor no ombro, no entanto essa relação em adolescentes atletas ainda não é bem definida. $O$ objetivo deste estudo foi avaliar a prevalência de discinese escapular em adolescentes atletas amadores e sua associação com a dor e medidas de função no ombro.

MÉTODOS: 178 adolescentes do sexo masculino $(14,58 \pm 2,16$ anos) participaram do estudo. Os sujeitos responderam ao questionário Quick Disability Arm Shoulder Hand. Também foram avaliados massa corporal, estatura, rotação interna do ombro e Closed Kinetic Chain Upper Extremity Stability. Para avaliação da discinese escapular, utilizou-se o método visual dinâmico. A regressão logística binária foi utilizada para analisar a associação entre discinese e as demais variáveis. A comparação entre os grupos com e sem discinese foi feita pelo teste $t$ e Mann-Whitney, sendo aceito significância estatística quando $\mathrm{p}<0,05$.

RESULTADOS: A prevalência de discinese foi de 56,7\% e essa condição não teve associação com dor no ombro. Atletas mais jovens têm $159 \%$ mais chances de apresentar discinese, enquanto aqueles que treinam mais de uma hora por dia, durante três vezes por semana, têm $77 \%$ mais chances de ter o mesmo desfecho. Nenhuma diferença na função do ombro foi encontrada.

CONCLUSÁO: A discinese escapular não está associada à dor e não altera medidas de função no ombro em adolescentes atletas. Modalidade, idade e volume de treinamento parecem induzir mudanças na movimentação escapular.

Descritores: Adolescente, Atletas, Desempenho atlético, Dor, Ombro.

\section{INTRODUCTION}

Sports modalities requiring constant use of the upper limb increase the joint overloads on this segment, especially in the shoulder complex. ${ }^{1}$. It has been well documented in the literature that movements at high speed, repetition, and load trigger joint adaptations such as disproportion between internal and external shoulder rotation amplitudes and changes in humeral and scapular positioning ${ }^{1-5}$. Specifically, the modification in the scapula positioning, called scapular dyskinesis, has been studied because it presents possible relations with the presence of pain and shoulder injuries in athletes ${ }^{2,6-8}$.

Most of the studies state the relation between shoulder pain/ injury and scapular dyskinesis ${ }^{2,7,9-11}$. Such research ensures that 
changes in scapular kinematics may result in structural and functional changes in the glenohumeral and acromioclavicular joints, decreased subacromial space, changes in the scapular muscles activation and, consequently, leading to dysfunctions such as shoulder-rotator cuff syndrome, rotator cuff tendinopathies, glenohumeral instability, and other conditions. On the other hand, there is evidence that scapular asymmetries are also observed in asymptomatic subjects, and for this reason, it is not possible to clearly and accurately infer a cause-effect relationship between pain and dyskinesis, making it impossible to state which of these factors precedes the other ${ }^{12-16}$. It is noteworthy that a good part of these studies ${ }^{12-16}$, stating that there is a relationship between pain and dyskinesis, refers to the adult population or high-level competition athletes, which, possibly, by the repetitive motor movements and training overload may make this association more evident. Thus, it is possible to speculate if younger athletes, and with fewer sports requirements, would behave similarly to previous studies, but evidence that supports this inquiry is still insufficient $\mathrm{t}^{17,18}$.

Therefore, this study aimed at estimating the scapular dyskinesis prevalence in young amateur athletes, as well as evaluating the possible association between scapular dyskinesis and shoulder pain and identifying whether this condition influences the shoulder function of adolescent athletes.

\section{METHODS}

This is a cross-section, observational, descriptive and correlational study. The sample consisted of male adolescents, practicing the following sports: volleyball, swimming, handball, basketball, and judo from the city of Petrolina, PE. The inclusion criteria were: be between 10 and 19 years old and have been practicing sports for at least one year. Exclusion criteria were not submitting the Informed Free and Informed Consent Form (FICT) signed by the legal representatives together with the Free and Informed Acknowledgment Form, who refused to perform the tests and/or inadequately completed the questionnaire.

Three hundred and seventeen adolescents were evaluated, aged between 10 and 19 years, of both genders, randomly selected after a probabilistic sampling procedure, determining a minimum sample of 290 athletes based on the representativeness of the five modalities. However, this study's sample was composed only of male adolescents $(n=180)$, since the female athletes did not feel comfortable to perform the dyskinesis evaluation. Therefore, for the purpose of this analysis, the sampling power calculation was performed posteriori using the GPower software.

Initially, a questionnaire containing personal and sports data (age, sports modality, total sports practice time, training frequency on days per week, duration of the training session in hours per day, the presence of shoulder pain) was applied. The subjects answered questions from the Corlett's Body Diagram ${ }^{19}$ to check for the presence or absence of shoulder pain. In addition, the QuickDASH (Quick Disability Arm Shoulder Hand) questionnaire was applied with its optional practicing module (Quick-DASH optional). This instrument was translated and validated for adolescents ${ }^{20}$ which evaluates the upper limb as a functional unit and presents internal consistency of $\alpha=0.91^{20}$. The anthropometric variables (body mass and height) according to the International Society for the Advancement of Kinanthropometry (ISAK) standardization and body mass index (BMI) were calculated using the equation BMI = Body Mass $/(\text { Height })^{2}$. The criteria suggested by the International Obesity Task Force (IOTF) were used to classify adolescents' nutritional status ${ }^{21}$.

The range of motion of the internal shoulder rotation was measured using the passive motion technique with a goniometer. For this, the subjects remained in the supine position bent knees and hips, abducted arm and elbow bent at $90^{\circ 21,22}$. The goniometer axis was aligned in the olecranon process, the arm fixed perpendicularly to the floor and the mobile in parallel to the styloid process of the subject's ulna. The final range of motion criteria for internal rotation was the combination of end feel and visualization of scapular compensation (anterior tilt). In the cases of subjects with shoulder pain, the range limit was established by the initial (reported or expressed) sensation of pain. The measurement was performed by a single evaluator. Three measurements were performed on both limbs, and a final value was taken from the angles average. The calculation of the glenohumeral internal rotation deficit was taken by subtracting the internal rotation values of the dominant and non-dominant limbs. According to Wilk et al. ${ }^{24}$, it was established a difference greater than $18^{\circ}$ to categorize the volunteers with internal rotation deficits.

Scapular movement was evaluated by the dynamic observational method. In this method, the volunteer was asked to remain in the orthostatic position and perform three repetitions of the bilateral arm elevation movement in the scapular plane up to $90^{\circ}$. The movement speed was standardized in three seconds for concentric phase and three seconds for eccentric phase through examiners verbal command. The movement execution was recorded in a posterior view by a digital camcorder with a sampling frequency of $60 \mathrm{~Hz}$ (SONY model DCR-SX21), positioned on a tripod $1.00 \mathrm{~m}$ high in relation to the floor and at 2.85 meters from the subject. Ground markings were used to standardize the position of the camcorder and the volunteers ${ }^{25}$.

The categorization of the scapular dyskinesis type was performed according to Kibler et al. ${ }^{26}$ guidelines. The visualization of the prominence of the scapula's lower angle was interpreted as type I; type II, those representing the medial edge prominence increase; type III those characterized by upper angle excessive elevation; and type IV those indicating the absence of scapular dyskinesis. Once the asymmetry was identified in several planes, a duly qualified evaluator classified dyskinesis in one of these four types, based on the predominant pattern ${ }^{13}$. In a second moment, all the volunteers classified with scapular dyskinesis (types I to III) were grouped into a single category: "with scapular dyskinesis" and those classified as type IV were included in the "without scapular dyskinesis" category ${ }^{13}$.

Finally, to assess the upper limb stability, the volunteer was asked to perform the Closed Kinetic Chain Upper Extremity Stability Test (CKCUES-Test). In that test, the volunteers remained in the push-up position with their hands resting on two tapes fixed to the ground at a distance of 36 inches $(91.4 \mathrm{~cm})$. The volunteer should hold this position while alternately performing the move- 
ment of touching the opposite hand for 15 seconds. Three maximal repetitions with a 45 -second interval between trials were performed. Before performing the test, the volunteers performed three submaximal tests in order to familiarize them with the task. One evaluator was responsible for counting the touch number and the other for measuring time and verbally informing the first evaluator of the test start and end. The touch mean obtained was multiplied by $68 \%$ of the body weight in kilograms and divided by 15 to obtain the test power score ${ }^{27}$.

Prior to data collection, a pilot test was conducted with 25 adolescents to verify the level of agreement between the measures (with a one-week interval between evaluations). For the numerical variables we used the Intraclass Correlation Coefficient (ICC) test, and for the dyskinesis categorization, the Kappa's index. Numerical variables showed coefficient body mass and height of 0.99, Quick-DASH of 0.81, optional Quick-DASH 0.73 , CKCUES-test of 0.87 and internal rotation of 0.82 for the right shoulder and 0.91 for the left shoulder. Kappa's index for scapular dyskinesis presence or absence was 0.99. All measurements indicate excellent reliability. These 25 volunteers were not part of the final sample of the study, and the same evaluator who performed those measurements was responsible for them out in the larger study.

This study was approved by Ethics Committee of the University of Pernambuco CAAE 38321114.0.0.0000.5207.

\section{Statistical analysis}

Data's statistical analysis was performed using the Statistical Package for the Social Sciences (SPSS) software version 20. Categorical data description was represented by absolute and relative frequency and mean/median values and interquartile standard deviation/range were used to describe the numerical data depending on the normality of data distribution. For this, the data distribution inferential analysis was carried out by the Kolmogorov-Smirnov test. In addition, the Chi-square test, $\mathrm{t}$ test for independent samples and Mann-Whitney were used to observe the differences between the analyzed variables and subjects with and without scapular dyskinesis. In order to verify the association between the dyskinesis presence and the personal, sports and pain characteristics, a bivariate model of association between dyskinesis presence and each independent variable was constructed in order to observe which variables would enter the model $(\mathrm{p}<0.20)$. In this analysis, odds ratios (ORs) and $95 \%$ confidence intervals were used to express the association degree between variables. Then, binary logistic regression was performed to explore possible confounding and interaction factors, and to identify the need for analyzes statistical adjustment.

Binary logistic regression with a step-by-step strategy for the analysis was chosen. Only the variables presenting $\mathrm{p}<0.20$ were inserted into the final model. Omnibus test and Hosmer-Lemeshow value were analyzed to confirm the model's validity. Finally, for shoulder function measurements comparison in adolescents with and without scapular dyskinesis, the Mann-Whitney test was used. All tests considering a level of significance of less than $5 \%$.

\section{RESULTS}

One hundred and eighty male adolescent athletes were included in the study. However, two volunteers were excluded by the exclusion criteria because they refused to perform scapular dyskinesis assessment, totaling 178 subjects. The posteriori sampling power, based on the final logistic regression model, indicates that for a $\alpha=0.05$ with four predictors in the final model and $\mathrm{R}^{2}=0.227$, the statistical power of this study represents $99 \%$. The average age was $14.58 \pm 2.16$ years, and the most practiced sports by adolescents were handball and basketball. The description of the anthropometric data, sports characteristics and their respective frequencies according to the presence or absence of scapular dyskinesis is presented in table 1 .

The prevalence of scapular dyskinesis in this sample was $56.7 \%$. From these, $46.5 \%$ were classified with type I dyskinesis, $43.6 \%$ with type II and $9.9 \%$ with type III. Table 2 shows the associa-

Table 1. Personal and sports characteristics of the total sample and stratified by absence and presence of scapular dyskinesis. Numerical values represented in average and standard deviation and categorical in absolute and relative frequency $(n=178)$

\begin{tabular}{|c|c|c|c|c|}
\hline Personal characteristics & Total & Without dyskinesis & With dyskinesis & $\mathrm{p}$ value \\
\hline Age (years) & $14.58(2.16)$ & $14.78(2.26)$ & $14.44(2.07)$ & 0.206 \\
\hline Body mass, (kg) & $63.27(15.52)$ & $65.10(15.03)$ & $61.88(15.82)$ & 0.167 \\
\hline Height (m) & $1.70(0.12)$ & $1.70(0.12)$ & $1.70(0.12)$ & 0.639 \\
\hline Body mass index $\left(\mathrm{kg} / \mathrm{m}^{2}\right)$ & 21.62 (3.92) & $22.39(3.94)$ & $21.03(3.81)$ & $0.011^{*}$ \\
\hline \multicolumn{5}{|l|}{ Sports characteristics } \\
\hline $\begin{array}{l}\text { Modalities } \\
\text { Basketball } \\
\text { Handball } \\
\text { Judo } \\
\text { Swimming } \\
\text { Volleyball }\end{array}$ & $\begin{array}{l}44(24.7 \%) \\
48(27.0 \%) \\
18(10.1 \%) \\
32(18.0 \%) \\
36(20.2 \%)\end{array}$ & $\begin{array}{c}13(16.9 \%) \\
21(27.3 \%) \\
7(9.1 \%) \\
14(18.2 \%) \\
22(28.6 \%)\end{array}$ & $\begin{array}{l}31(30.7 \%) \\
27(26.7 \%) \\
11(10.9 \%) \\
18(17.8 \%) \\
14(13.9 \%)\end{array}$ & $0.012^{*}$ \\
\hline $\begin{array}{l}\text { Practice time } \\
1 \text { year } \\
\text { More than } 1 \text { year }\end{array}$ & $\begin{array}{c}43(24.2 \%) \\
135(75.8 \%)\end{array}$ & $\begin{array}{l}25(32.5 \%) \\
52(67.5 \%)\end{array}$ & $\begin{array}{l}18(17.8 \%) \\
83(82.2 \%)\end{array}$ & $0.037^{*}$ \\
\hline Years of practice & $4.76(2.99)$ & $4.77(3.04)$ & $4.75(2.98)$ & 0.980 \\
\hline
\end{tabular}


Table 1. Personal and sports characteristics of the total sample and stratified by absence and presence of scapular dyskinesis. Numerical values represented in average and standard deviation and categorical in absolute and relative frequency $(n=178)$ - continuation

\begin{tabular}{lccc}
\hline Personal characteristics & Total & Without dyskinesis & With dyskinesis \\
\hline Frequency of training (times/week) & & & \\
Up to 3 & $135(75.8 \%)$ & $58(75.3 \%)$ & $77(76.2 \%)$ \\
More than 3 & $43(24.2 \%)$ & $19(24.7 \%)$ & $24(23.8 \%)$ \\
Duration of training session (hours/day) & & & 1.000 \\
Up to 1 hour & $30(16.9 \%)$ & $16(20.8 \%)$ & $14(13.9 \%)$ \\
More than 1 hour & $148(83.1 \%)$ & $61(79.2 \%)$ & $87(86.1 \%)$ \\
\hline
\end{tabular}

*Statistical difference.

tion between dyskinesis presence and the independent variables. Only the variables age ( 10 to $14: \mathrm{OR}=2.59$; CI $95 \%=1.27$ - 5.26); BMI (eutrophic: OR = 2.43; CI 95\% = 1.16 - 5.09); modality (basketball: $\mathrm{OR}=3.82$; CI $95 \%=1.41-10.35$; handball: $\mathrm{OR}=2.92$; CI 95\% $=1.09-7.80$; judo: $\mathrm{OR}=4.45$; CI $95 \%=1.20-16.52$ and swimming: $\mathrm{OR}=2.95$; CI $95 \%=0.96$ -9.05); and practice time and session duration $(\mathrm{OR}=0.23$; CI
$95 \%=0.08-0.66)$ remained in the final model. No confounding variable was found. The model validity was confirmed by the Omnibus test $(\mathrm{p}=0.001)$ with explanatory power of $89 \%$ by Hosmer-Lemeshow.

The comparison between upper limb function variables and scapular dyskinesis can be observed in table 3. No statistical differences were found between groups.

Table 2. Association of independent variables with the presence of scapular dyskinesis in adolescent athletes $(n=178)$

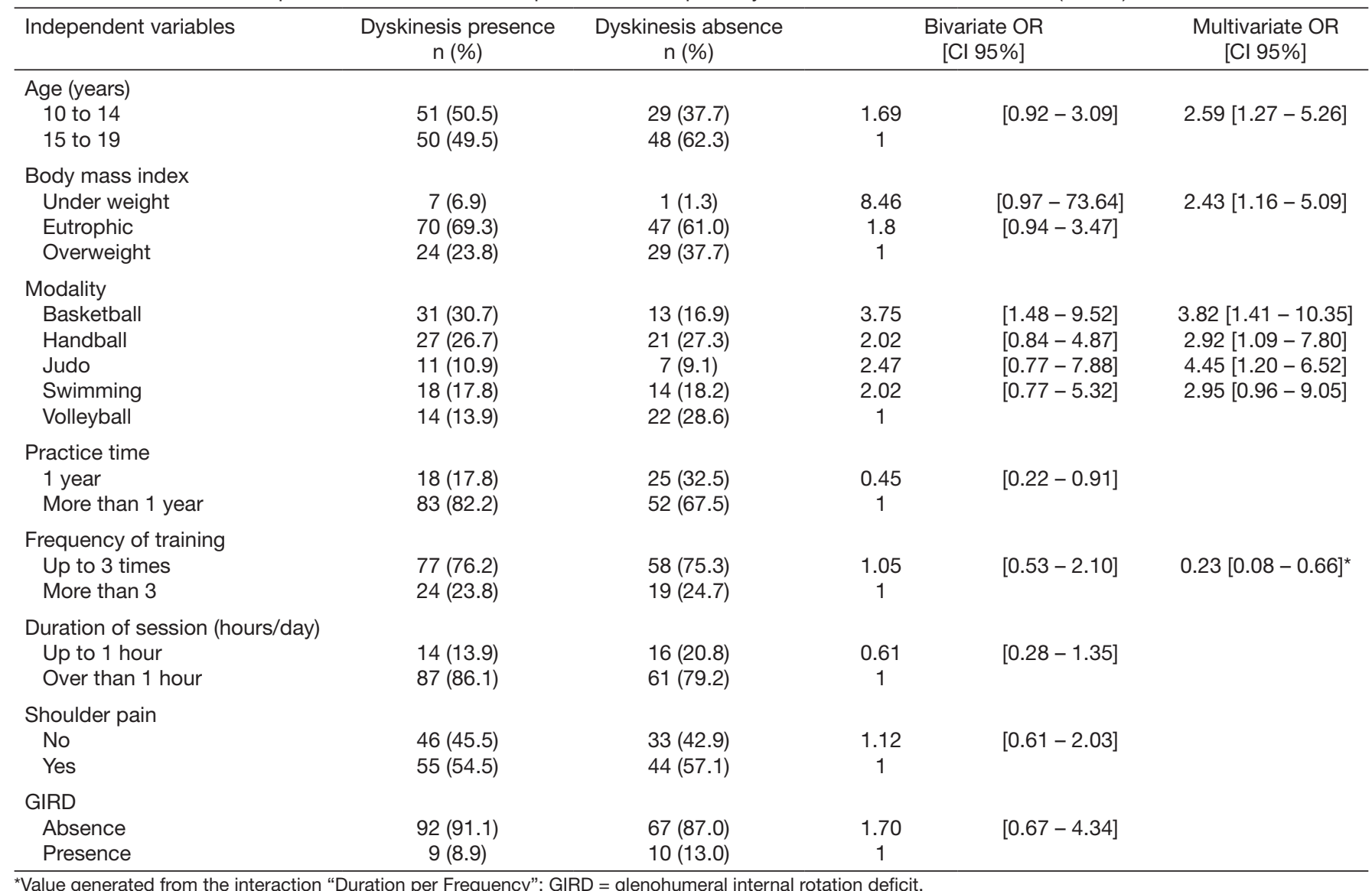

Table 3. Median (interquartile range) of shoulder function measurements among adolescents with and without scapular dyskinesis ( $n=178$ )

\begin{tabular}{lccc}
\hline Function measurement & With dyskinesis & Without dyskinesis & $p$ value \\
\hline Quick - DASH & $6.80(9.10)$ & $9.10(11.30)$ & 0.288 \\
Optional Quick - DASH & $0.00(12.50)$ & $0.00(12.50)$ & 0.979 \\
CKCUES-test & $69.20(35.60)$ & $60.40(25.40)$ & 0.079 \\
Internal rotation deficit & $8(8)$ & $9.00(10.00)$ & 0.563 \\
\hline
\end{tabular}

Quick-DASH = Quick Disability Arm Shoulder Hand; CKCUES-Test = Closed Kinetic Chain Upper Extremity Stability Test. 


\section{DISCUSSION}

Differences regarding the relationship between dyskinesis and shoulder pain motivated this study. Results indicate that for a population of adolescent athletes with an amateur sports level, the dyskinesis prevalence is high; however, it is not associated with pain and does not seem to affect measures of upper limb function.

Although some studies support the relationship between pain/ lesion and scapular dyskinesis ${ }^{2,7-11}$, more than half of the current sample $(56.7 \%)$ presented changes in scapular movement without, however, being associated with shoulder pain. The results of this study corroborate those of Oliveira et al. ${ }^{28}$ who analyzed amateur male athletes with shoulder injury syndrome and observed no association between dyskinesis and shoulder pain. In addition, Uhl et al. ${ }^{13}$ analyzed the scapular dyskinesis presence through the observational and kinematic 3D method between groups with and without shoulder pain. The authors reveal that the dyskinesis prevalence between the two groups was similar and concluded that the presence of this condition should not be considered a pathological sign, but a compensatory mechanism for individuals who use the upper limb intensely. In addition, it is suggested that the asymmetry presence should not be the only factor that determines the clinical significance of scapular dyskinesis and that bilateral asymmetries are frequent. Thus, it is speculated that the scapular dyskinesis in amateur athletes may be attributed more to the adaptive attitudes of the sports movement than to the presence of pain itself.

Indeed, the lack of longitudinal studies makes it difficult to discern whether the observed changes in the scapular movement are compensatory attitudes of an already installed lesion or if the uncoordinated movement results in injurious mechanisms. Under this perspective, Myers, Oyama e Hibberd ${ }^{16}$ proposed to prospectively evaluate if scapular dyskinesis identified in the pre-season of adolescent baseball athletes could be a predisposing factor to the risk of shoulder injuries in athletes and could conclude that the dyskinesis presence does not increase the risk of upper limb lesions.

Sports factors are associated with scapular changes presence. In this study, it was possible to observe that adolescent athletes are more likely to be classified with dyskinesis according to the greater training volume, and in general, sports modalities also increase the probability of individuals having dyskinesis. Adolescents training in smaller magnitude (up to three times a week for less than one hour per day) are 64\% less likely to have scapular dyskinesia. In the same vein, Madsen et al. ${ }^{15}$ proposed to evaluate the evolution of the scapular dyskinesis prevalence during a single training session in asymptomatic elite young athletes (14 to 22 years old). Authors used the observational method to evaluate the dyskinesis occurrence before, and at 25, 50, 75 and 100 minutes of training. Their results showed a cumulative dyskinesis prevalence of $82 \%$ in the last session interval (100 minutes of training), and suggest that scapular dyskinesis may be a result of muscle fatigue as a consequence of the high volume of training ${ }^{15}$. It was also found in this study that measures of shoulder function are similar among athletes with and without scapular dyskine- sis. This condition's presence was not enough to reflect on upper limb functional impairment according to the questionnaires applied. In addition, the CKCUES-test power values and the internal rotation deficit, conditions that are related to the presence of shoulder pain in previous studies ${ }^{3,24,27}$ were not different between the groups with and without scapular dyskinesis. Thus, it is speculated that functional alterations may be related to pain complaint and not to changes in scapular positioning. However, the absence of studies regarding the influence of scapular dyskinesis on indicators of upper limb function in adolescent athletes limits the in-depth discussion of these results.

Since motor skills can be influenced by factors such as strength, flexibility and muscular endurance, and these are improved over time, kinematic differences in the scapula and muscle action are found in children and adolescents athletes compared to adults ${ }^{17,18,29}$. In the present sample, younger athletes (10 to 14 years old) were $159 \%$ more likely to have dyskinesis. This reinforces the hypothesis that scapular dyskinesis in adolescents may be once again attributed to compensatory actions through motor action in sport combined with immaturity in motor skills. However, the appearance of a medium- or long-term pain as a result of this scapular dysrhythmia is still a limited and inconclusive questioning.

In the current sample, underweight and eutrophic adolescents were more likely to be classified with scapular dyskinesis. These results may not be related to the anthropometric characteristics themselves, but rather to the limitations of a proposed instrument for scapular dyskinesis analysis. Because it is a visual method, Uhl et al. ${ }^{13}$ confirm the difficulty in accurately observing the scapular movements under the underlying muscle and soft tissues. It implies, therefore, that subjects with less tissue adjacent to the scapula, either subcutaneous or muscular, allow a better visualization of the bony prominences, which has justified the high odds of identifying dyskinesis in these subjects in the current study. Although the observational method presents some limitations, it is considered the most applicable for clinical and sportive practice and presents good reliability and validity compared to the kinematic 3D analysis method ${ }^{13,16}$.

This study was concerned with reducing possible biases due to the limitations found. The cross-sectional delineation is a factor that restricts further conclusions about cause-and-effect. However, information obtained through a representative sample may serve as a subsidy for future studies with longitudinal designs in adolescents. Another limitation refers to the extrapolation of the results found, which is directed to male amateur athletes of the evaluated modalities. This second limitation offers a field of study with both genders and/or with different sports levels. Other variables, which were not measured in this study, could also have influenced scapular dyskinesis, such as rotator cuff strength or cervicothoracic motion. Thus, not all potential variables were or could not be measured, but there may be evidence of its association with dyskinesis. Finally, another limitation is related to not having established a moment of pain symptoms occurrence in the shoulder. In this study, any occurrence of shoulder pain during the subject's life was analyzed, which may have overestimated the results. 


\section{CONCLUSION}

Scapular dyskinesis is not associated with pain and does not alter measures of shoulder function in amateur adolescent athletes. Specific sports for upper limbs, age, and training volume may increase the chances of scapular movement, so the dyskinesis presence can be attributed to the compensatory mechanisms of motor movement, not necessarily to shoulder pain.

\section{REFERENCES}

1. Beckett M, Hannon M, Ropiak C, Gerona C, Mohr K, Limpisvasti O. Clinical assessment of scapula and hip joint function in preadolescent and adolescent baseball players. Am J Sports Med. 2014;42(10):2502-9.

2. Kibler WB, Sciascia A, Wilkes T. Scapular dyskinesis and its relation to shoulder injury. J Am Acad Orthop Surg. 2012;20(6):364-72.

3. Astolfi MM, Struminger AH, Royer TD, Kaminski TW, Swanik CB. Adaptations of the shoulder to overhead throwing in youth athletes. J Athl Train. 2015;50(7):726-32.

4. Cools AM, Johansson FR, Borms D, Maenhout A. Prevention of shoulder injuries in overhead athletes: a science-based approach. Braz J Phys Ther. 2015;19(5):331-9.

5. Guney H, Harput G, Colakoglu F, Baltaci G. The effect of glenohumeral internal-rotation deficit on functional rotator-strength ratio in adolescent overhead athletes. J Sport Rehabil. 2016;25(1):52-7.

6. Struyf F, Nijs J, De Graeve J, Mottram S, Meeusen R. Scapular positioning in overhead athletes with and without shoulder pain: a case-control study. Scand J Med Sci Sports. 2011;21(6):809-18.

7. Kibler WB, Ludewig PM, McClure PW, Michener LA, Bak K, Sciascia AD. Clinical implications of scapular dyskinesis in shoulder injury: the 2013 consensus statement from the "Scapular Summit". Br J Sports Med. 2013;47(14):877-85.

8. Kibler WB, McMullen J. Scapular dyskinesis and its relation to shoulder pain. J Am Acad Orthop Surg. 2003;11(2):142-51.

9. Ludewig PM, Reynolds JF. The association of scapular kinematics and glenohumeral joint pathologies. J Orthop Sports Phys Ther. 2009;39(2):90-104.

10. Clarsen B, Bahr R, Andersson SH, Munk R, Myklebust G. Reduced glenohumeral rotation, external rotation weakness and scapular dyskinesis are risk factors for shoulder injuries among elite male handball players: a prospective cohort study. Br J Sports Med. 2014;48(17):1327-33.

11. Timmons MK, Thigpen CA, Seitz AL, Karduna AR, Arnold BL, Michener LA. Scapular kinematics and subacromial-impingement syndrome: a meta-analysis. J Sport Rehabil. 2012;21(4):354-70.

12. Oyama S, Myers JB, Wassinger CA, Daniel Ricci R, Lephart SM. Asymmetric resting scapular posture in healthy overhead athletes. J Athl Train. 2008;43(6):565-70.

13. Uhl TL, Kibler W Ben, Gecewich B, Tripp BL. Evaluation of clinical assessment methods for scapular dyskinesis. Arthroscopy. 2009;25(11):1240-8.

14. Struyf F, Nijs J, Meeus M, Roussel NA, Mottram S, Truijen S, et al. Does scapular positioning predict shoulder pain in recreational overhead athletes? Int J Sports Med. 2014;35(1):75-82.

15. Madsen PH, Bak K, Jensen S, Welter U. Training induces scapular dyskinesis in painfree competitive swimmers: a reliability and observational study. Clin J Sport Med. 2011;21(2):109-13

16. Myers JB, Oyama S, Hibberd EE. Scapular dysfunction in high school baseball players sustaining throwing-related upper extremity injury: a prospective study. J Shoulder Elbow Surg. 2013;22(9):1154-9.

17. Dayanidhi S, Orlin M, Kozin S, Duff S, Karduna A. Scapular kinematics during humeral elevation in adults and children. Clin Biomech. 2005;20(6):600-6.

18. Struyf F, Nijs J, Horsten S, Mottram S, Truijen S, Meeusen R. Scapular positioning and motor control in children and adults: a laboratory study using clinical measures. Man Ther. 2011;16(2):155-60.

19. Corlett EN, Manenica I. The effects and measurement of working postures. Appl Ergon. 1980;11(1):7-16.

20. Quatman-Yates CC, Gupta R, Paterno MV, Schmitt LC, Quatman CE, Ittenbach RF Internal consistency and validity of the Quick DASH instrument for upper extremity injuries in older children. J Pediatr Orthop. 2013;33(8):838-42.

21. Cole TJ, Bellizzi MC, Flegal KM, Dietz WH. Establishing a standard definition for child overweight and obesity worldwide: international survey. BMJ. 2000;320(7244):1240-3.

22. Wilk KE, Obma P, Simpson CD, Cain EL, Dugas JR, Andrews JR. Shoulder injuries in the overhead athlete. J Orthop Sports Phys Ther. 2009;39(2):38-54.

23. Myklebust G, Hasslan L, Bahr R, Steffen K. High prevalence of shoulder pain among elite Norwegian female handball players. Scand J Med Sci Sports. 2011;23(3):288-94.

24. Wilk KE, Macrina LC, Fleisig GS, Porterfield R, Simpson CD 2nd, Harker P, et al. Correlation of glenohumeral internal rotation deficit and total rotational motion to shoulder injuries in professional baseball pitchers. Am J Sports Med. 2011;39(2):329-35.

25. Kibler WB, Sciascia A. Current concepts: scapular dyskinesis. Br J Sports Med. 2010;44(5):300-5.

26. Kibler WB, Uhl TL, Maddux JW, Brooks PV, Zeller B, McMullen J. Qualitative clinical evaluation of scapular dysfunction: a reliability study. J Shoulder Elbow Surg. 2002;11(6):550-6

27. Tucci HT, Martins J, Sposito Gde C, Camarini PM, de Oliveira AS. Closed kinetic chain upper extremity stability test (CKCUES test): a reliability study in persons with and without shoulder impingement syndrome. BMC Musculoskelet Disord. 2014;15:1.

28. Oliveira VM, Batista LD, Pitangui AC, Araújo RC. Effectiveness of Kinesio Taping in pain and scapular dyskinesis in athletes with shoulder impingement syndrome. Rev Dor. 2013;14(1):27-30.

29. Endo K, Yukata K, Yasui N. Influence of age on scapulo-thoracic orientation. Clin Biomech. 2004;19(10):1009-13. 